American Journal of Environmental Sciences 5 (2): 130-136, 2009

ISSN 1553-345X

(C) 2009 Science Publications

\title{
Evolution of a Graduate Environmental Science Program
}

\author{
Will Focht and Talya Henderson \\ Environmental Science Graduate Program, Oklahoma State University, \\ 002 Life Science East, Stillwater, Oklahoma, USA 74078-3011
}

\begin{abstract}
Problem statement: Environmental science programs vary widely in their curricula and pedagogical approaches. In part, this is due to the lack of a unified agreement on field identity. However, program differences are also the product of variable program histories. Approach: This essay described the founding and subsequent history of the Environmental Science Graduate Program at Oklahoma State University, its oldest and largest interdisciplinary program. An evaluation of this history was conducted to discern what lessons could be learned that may prove valuable to the establishment and operation of interdisciplinary programs elsewhere. Results: The 31-year history of OSU's environmental science graduate program can be described as occurring in six evolutionary stages-from the circumstances that created the opportunity for its establishment as a program located in the graduate college, through slow growth, rapid expansion and maturation, uncertainty and institutional change, retrenchment and revitalization, and finally, relocation within the college of arts and sciences. Each new stage was triggered primarily by decisions of university administration and to a lesser extent by a change in program leadership. Conclusion: The lessons learned from our analysis of this history suggests that the success of interdisciplinary programs hinges on energetic, dedicated and risk-taking program directors; political and financial support from higher administration; support of affiliated faculty; cooperation with, or at least tolerance from, traditional departments; and creation of a sense of community and shared purpose among faculty, students, alumni, employers and donors.
\end{abstract}

Key words: Environmental science, interdisciplinary programs, program history

\section{INTRODUCTION}

The Environmental Science Graduate Program is the oldest and largest interdisciplinary program at Oklahoma State University. Like other interdisciplinary programs at OSU and other institutions of higher education, the history of this program is complex and non-linear. This essay presents an account of this history and identifies lessons derived from it that can inform the establishment and maintenance of interdisciplinary programs elsewhere.

\section{MATERIALS AND METHODS}

The researchers consulted published histories of research and graduate education at OSU and conducted interviews of past program directors to develop this account of the environmental science graduate program. This essay concludes with a critical reflection on this history in order to identify the factors that we believe contribute to interdisciplinary program success.
The history of the environmental science graduate program can be summarized in six evolutionary stagesfrom pre-program context to program future.

Stage 1 (1962-1977)-forces of creation: Four forces converged to create the impetus for establishment of a graduate environmental science degree program at OSU.

The first of these forces was the burgeoning environmental movement that arguably began in 1962 with the publication of Rachel Carson's Silent Spring ${ }^{[1]}$ and that led to the first Earth Day celebration on April 22, 1970. This movement raised the environmental consciousness of the OSU community just as it had at other college campuses across the nation.

The second force was the rapidly growing federal presence in environmental regulation during the late 1960s and 1970s. Perhaps most important was the creation of the US Environmental Protection Agency by President Richard Nixon on December 1, 1970. The enactment of several important pieces of legislation strengthened this presence, including the national

Corresponding Author: Will Focht, Environmental Science Graduate Program, Oklahoma State University, 002 Life Science East, Stillwater, USA 74078-3011 
environmental policy act; endangered species act; resource conservation and recovery act; toxic substances control act; safe drinking water act; noise control act; federal insecticide, fungicide and rodenticide act; and landmark amendments to both the clean air and clean water acts. These programs created occupational opportunities for trained environmental scientists.

Student demand was the third force. Graduate students interested in environmental careers desired a degree that included a curriculum extending beyond a single discipline ${ }^{[2]}$.

The growing support of environmental research at OSU was the fourth force. Three environmental research centers were established at OSU between 1965 and $1967^{[3]}$. These organizations awarded seed grants to conduct research that could lead to the preparation of competitive extramural grant proposals, which stimulated interest in environmental research among both faculty and graduate students:

- The Oklahoma Water Resources Research Institute was established in 1965 as one of 54 state and territorial water research institutes authorized by federal Water Resources Research Act of 1964. The OWRRI was located within the OSU's Research Foundation

- The Water Research Center (WRC) and the University Center for Energy Research (UCER) was established in 1967 with a \$100,000 appropriation from the Oklahoma Legislature. The Dean of the Graduate College was appointed director of both centers

- In 1972, these three organizations were consolidated into one: the Environmental Institute (EI). The EI was located within the office of the Vice President for Academic Affairs and Research

Stage 2 (1977-1982)-modest beginnings: Stimulated by the confluence of these forces, an ad hoc committee chaired by the Dean of the Graduate College formulated a proposal for the creation of a graduate environmental science degree. The committee included representatives from geography, geology, civil engineering, agricultural economics, zoology, education, political science, sociology and home economics. Fearing increased competition for resources, college deans were skeptical initially. Their concerns were ameliorated by the requirement that each student seeking the environmental science degree must first fulfill degree requirements within an existing department and then add courses from other disciplines. The student's transcript would thus show a degree in environmental science with a concentration in the home department's discipline. In this way, enrollments within existing degree-granting departments would not be adversely affected. The OSU Regents approved the Environmental Sciences (ES) Graduate Program in the spring of 1977.

Program administration was accomplished through an Environmental Sciences Steering Committee, chaired by the Graduate College Dean and comprised of the members of the ad hoc committee that proposed the program plus faculty representatives from economics and forestry. The Committee was charged with setting admission and graduation standards, screening student applications and approving plans of study. One member of every student's graduate committee was required to be a member of the Steering Committee.

Considerable early discussion among Committee members concerned whether the program should be structured as multidisciplinary (requiring ES students to take a range of unidisciplinary courses from existing departments) or interdisciplinary (requiring students to take one or more integrated courses developed from within the program). Limited resources to create and teach interdisciplinary courses settled the matter in favor of a multidisciplinary curriculum.

The ES program admitted its first two students in the summer of 1977 as transfers from other masters' degree programs. They both graduated later that same year. In 1982, the program graduated its first Ph.D. student.

In 1978, the Graduate Dean appointed the geography department head as coordinator of the program and chair of the Steering Committee. The coordinator developed the first interdisciplinary course under the program's own prefix, ENVIR. In the course, students formed teams and prepared environmental impact statements on projects of their choice. Offered once per year, it served as the program's capstone; faculty from several disciplines participated in its teaching.

Initial growth in enrollment was slow. Most departments discouraged students from seeking the ES degree. Students from geography, geology, home economics and education dominated early enrollments probably because these departments did not offer doctoral degrees. At the end of five years, only four students were enrolled.

Stage 3 (1982-1992)-rapid growth and program maturation: In 1982, the Graduate Dean appointed the Assistant Dean of the Graduate College as program coordinator after the original coordinator left on sabbatical. The Steering Committee was asked to 
reassess the program and offer recommendations for its invigoration. The following changes were made:

- All student applicants were required to submit a statement of their career goals and degree objectives as well as three letters of reference. Applicants who wanted to be considered for a water fellowship were required to take the Graduate Record Exam

- The need for students to complete all course requirements for degrees within individual departments was eliminated. Plans of study were now controlled entirely by the Steering Committee

- The capstone course was rotated among Steering Committee members and taught as a special topics course

- Curriculum rigor was increased through the requirement that all plans of study had to include physical sciences, biological sciences (including natural ecology) and social sciences

- Curriculum specializations were created in natural resources, water, energy and education to provide more structure to plans of study

- A part-time graduate assistant was hired to assist in program administration

In 1988, the position of program coordinator was elevated to director. Administrative and financial support of the program continued to be provided by the Graduate College; no specific program budget was allocated.

In 1989, ES students organized the first student organization dedicated to environmental issues. The Society of Environmental Scientists admitted any OSU student interested in the environment. Also in 1989, the ES program obtained its first seat on the Graduate Student Council. Before then, only department-based degree programs were represented.

By 1992, program enrollment grew to nearly 100 students. The program was clearly on solid ground.

Stage 4 (1992-2001)-institutional change: Rapid change in program location and administration began in 1992. The positions of Graduate Dean and Vice President for Research were combined and the administration of the ES program was moved from the Graduate College to the office of the Vice President for Research under the Environmental Institute. The position of EI director was elevated to Associate Dean for Multidisciplinary Studies and filled by the former head of the geography department. In 1993, another ES master's degree student was hired as administrative assistant who initiated a monthly newsletter that informed students about upcoming courses and other items of interest.

The Steering Committee now included representatives from agronomy, landscape architecture, entomology, botany, forestry, zoology, geography, civil and environmental engineering, biosystems engineering, political science, sociology, economics, agricultural economics, leisure sciences, education and human environmental sciences (formerly home economics). Changes to the program included the following:

- All applicants are required to take the GRE

- No student can be admitted unless he or she had already recruited a faculty advisor

- A fifth thrust area (policy) was added to the curriculum

- A second interdisciplinary course-environmental problem analysis-was added to the ENVIR core curriculum

- Office space was provided to ES students

- The ES program established a presence at OSU's campus in Tulsa. Two ENVIR courses were taught by local adjunct faculty (environmental chemistry and environmental sociology) and three more courses were taught by various Stillwater campus faculty members who traveled to Tulsa. By 1995, ten students were enrolled at Tulsa

In 1995, the Vice President for Research appointed a zoologist to head the program, under the new title of Associate Dean for Graduate Education and Director. These changes were made during the following year:

- The program name was changed from environmental sciences to environmental Science to reflect its integrated disciplinary vision

- Minimum GRE scores for admission were defined

- Program recruitment efforts were expanded through mailing of posters to 400 universities and travel to neighboring states

- The program received its first dedicated budget

- The program's first full-time permanent staff position was created and filled

- The program's first part-time faculty appointment was made to teach core courses

In 1996, the Vice President for Research appointed a chemist/electrical engineer as Associate Dean and Director, who served until the end of 2001. Like those before, he instituted changes: 
- To meet a growing need for upgraded knowledge and skills among practicing environmental professionals, a specialization in environmental management was created in 1998 and headed by a part-time faculty member in Tulsa

- Plans were made for the establishment of specializations in ecological risk assessment as well as environmental chemistry and toxicology as joint ventures between the ES program and the zoology and chemistry departments

- Distance education was encouraged through conversion of some environmental science courses to formats suitable for compressed video and internet offering

- An interactive electronic program was recorded on compact disc was prepared and distributed to potential student applicants at various venues around the State

- Thrust areas were eliminated in favor of increased flexibility in the design of plans of study

- The program was provided office space in Tulsa and a part-time faculty member was employed. Five additional courses were created: environmental standards, environmental chemistry I and II, environmental management practicum and environmental management internship. Tulsa enrollment rose to 20

In 1998, the program's leadership position was changed back to director when the positions of Vice President for Research and Graduate Dean were again separated in 2001. The ES program remained within the Environmental Institute under the office of the Vice President for Research, however.

Stage 5 (2002-2008)-retrenchment and revitalization: For the first eight months of 2002, the position of director of the Environmental Institute (and its ES program) remained unfilled. During the summer of that year, the ES program was moved from the EI back to the Graduate College. In August, the newly appointed Graduate Dean and the recently appointed Vice President for Research and External Relations jointly selected a political scientist and graduate of the ES program as the seventh director.

Beginning in 2003, the ES program experienced a series of financial and administrative challenges:

- In May 2003, OSU faced a significant budget shortfall. The newly appointed OSU President eliminated State funding of the Environmental Institute. As a result, water fellowships and student travel awards were eliminated and recruitment efforts and outreach operations were significantly reduced. University-wide budget cuts in 2004 reduced funds even more. The part-time faculty position in Tulsa was also eliminated

- In September 2003, the position of Graduate Dean was filled with an interim appointment and a newly redefined Vice President for Research and Technology Transfer position was filled. In 2004, a permanent appointment of Graduate Dean was made

- The building that housed ES student offices was razed in 2006; no substitute space was provided

Despite and because of these setbacks, however, the program sped up its evolution:

- The Steering Committee was reorganized as the Steering Council with its business divided among three committees. The Admission and Retention Committee was charged with defining admissions criteria, judging applications and reviewing the matriculation progress of students through the program. The Curriculum and Assessment Committee is responsible for defining the core curriculum, reviewing new course proposals and course changes, assessing course performance and defining program assessment criteria. The Awards and Events Committee plans special events and selects environmental award winners

- Steering Council members included faculty from biosystems engineering, civil and environmental engineering, chemical engineering, geology, zoology, plant and soil sciences, entomology, geography, agricultural economics, human environmental sciences, leisure studies, agricultural education, education and psychology

- The program's first strategic plan was developed and approved in 2004. Environmental sustainability was adopted as the program's core principle

- Program policies and procedures were clarified and published. Standardized procedures now govern the conduct of doctoral qualifying exams, thesis and dissertation defenses, admissions, retention, student committee composition, internships, course reviews and hours required for graduation

- An external advisory board was established in 2004, comprised of 20 leaders of environmental consulting firms, financial investment firms, law firms and industrial corporations. Three of the board's members are OSU environmental science 
graduates. The board meets twice each year to provide advice and support

- Databases were established to track student matriculation, help students develop plans of study and recruit members to their graduate committees, and match students to employers and internship sponsors. A listserve was established to aid in recruiting advisors for prospective students

- Formal annual assessments of both student progress and faculty support are conducted each spring

- To increase the interdisciplinarity of the program's curriculum, several new courses were added. New lecture courses include watershed management, sustainability, environmental management systems, environmental impact assessment, environmental site assessment, global environmental standards, industrial ecology, hazardous waste management and social aspects of environmental management. New skills courses include environmental research proposal preparation and environmental research report preparation. New independent study courses include masters and doctoral versions of both environmental readings and special topics in environmental science. Each course integrates disciplinary perspectives and methods to address selected environmental themes and problems

- Additional new courses could include watershed planning, pollution prevention, quantitative environmental analysis, contaminant remediation, risk perception and communication, environmental education, human stressors on the environment, advanced environmental sustainability, environmental leadership and environmental conflict management

- Five new specializations were defined in sustainability; environmental chemistry, toxicology and risk assessment; water and watershed management; environmental policy and conflict management; and environmental education. A doctoral specialization in environmental disaster management was created but was discontinued when the Fire and Emergency Management Program in the Political Science Department obtained approval for its doctoral program in 2008

- The environmental problem analysis course was revised to be more interdisciplinary and now serves as the program capstone

- Students' committees must now include not only a member of the Steering Committee but also a member of a disciplinary group different from that of the Committee Chair (the six groups are biological sciences, humanities, physical sciences and technology, social sciences, education and medical sciences)

- Admission standards were raised yet again to require minimum grades in prerequisite courses in basic chemistry, biology and math. Minimum grades were also set for the two program core courses. Finally, all ES students must now complete a research methods course

- The ES program joined the Council of Environmental Deans and Directors in 2003-an organization representing 140 of the nation's environmental science and studies programs. The program director is chair of the Council's curriculum committee and is leading a multi-year national curriculum study funded by the National Council for Science and the Environment. One of the doctoral students in the program will base her dissertation on this study

- The program initiated an Environmental Awards Ceremony in 2003. Held each spring, the ceremony recognizes outstanding accomplishments in environmental research (faculty and student), environmental teaching (faculty), professional environmental practice (alumni), environmental service (OSU staff and student) and environmental sustainability (two Oklahoma companies or organizations). In addition, an accomplished and inspirational speaker is invited to deliver the keynote address. Most awards are named after distinguished OSU faculty or donors

- The program initiated a fundraising program. To date, it has obtained financial contributions to fund three research fellowships (in rural sustainability, environmental management and environmental policy) and the environmental awards ceremony

- A special session is now reserved at OSU's annual research symposium for ES students to present their research. The best research presentation is selected by our Awards and Events Committee and the winner receives the Outstanding Student Research Award at our annual awards celebration

- The Society of Environmental Scientists was revitalized in 2002 and now includes only ES students

- The administrative associate position was upgraded to program coordinator to better correspond to its expanded responsibilities

- Enrollment at OSU-Tulsa has increased from 20 to 45 students, which can be attributed to the hiring of a part-time coordinator there. The administration at OSU-Tulsa increased the number of ES courses that it would fund each year from five to eight 
Stage 6 (2008-)-relocation: In 2007, the University Provost established an Interdisciplinary Graduate Program Task Force to review OSU's 11 interdisciplinary programs and offer recommendations for their improvement. One of the Task Force's recommendations was to elevate the Environmental Science Graduate Program to a School of Environmental Science that would report to a newly created position of Associate Provost for Interdisciplinary Studies, which would allow the program to hire its own tenure-track interdisciplinary core faculty to teach interdisciplinary ENVR courses, lead interdisciplinary research projects and mentor interdisciplinary students. Such a reform would do much to advance the program's productivity and enhance its reputation as a national leader in innovative program design. However, the proposal was not accepted by the University Administration. Instead, on July 1, 2008, the program was moved from the Graduate College to the College of Arts and Sciences. The program director now administratively reports to the Associate Dean for Research in the College but maintains an academic control relationship with the Graduate Dean. Three-year term limits are set for the director. Governance of program operation remains with the Director and Steering Council, however.

Over the next three years, the program plans to conduct formal program assessments, expand and improve its interdisciplinary core curriculum, recruit more support among faculty from other departments and increase its budget. Some of the initiatives that are either underway or planned are listed below:

- The program has just finalized its program assessment protocol. The protocol will asses learning outcomes in three areas: breadth of knowledge, understanding and application in core areas of environmental science; depth of knowledge, understanding and application in the student's area of specialization; and environmental problem solving through interdisciplinary synthesis and analysis

- The program hopes to gain approval for the conduct of an external program assessment. The only external program review occurred in 1992. An external review will not only help improve the program but also offer an independent judgment of success and evaluation of resource needs. Having conducted reviews of six other programs, the current Director understands the powerful influence that external assessments can play in program improvement

- A search for student office space and space dedicated for faculty and students to interact continues
- The program will explore the offering of professional certificates that can be earned through the completion of six three-credit-hour courses offered at distance. Five certificates will be considered: environmental management, water and watershed management, environmental policy, education and sustainability. Certificate programs can serve four purposes: upgrade the skills and knowledge of practicing environmental professionals who may not be interested in pursuing another degree, recruit additional students to the ES program, establish an income stream and improve the program's reputation and relationships with potential employers and donors

\section{RESULTS AND DISCUSSION}

Establishing a new, innovative, interdisciplinary degree program is indeed challenging. Success often requires a fortuitous confluence of circumstances, modest initial expectations, patience, political acumen and committed leadership. This historical account testifies that this was the case with OSU's environmental science graduate program.

The first observation that can be drawn from a careful evaluation of this history is that each distinct stage in the program's evolution was triggered not so much by initiatives pursued by the program director but rather by decisions made by higher administration in the university.

For example, the program was moved three times, from the graduate college to the research division, then back to the graduate college, and finally to the arts and sciences college. Each move affects how the program is both funded and managed.

Another example is the influence of budgets. The program began with no dedicated budget, then a gradually increasing budget, followed by a substantial decline, and now with a much lower-though stablebudget. Budgets, of course, affect staffing, student support, program activities and purchasing.

Finally, the duties of the program manager changed over time as the program was moved and changes to the budget were made. The directorship started out as a part-time coordinator position, increased in stature to a director position, then increased further to an associate dean position, and finally moved back to a director position. These changes affect the level of influence that the program manager has on program funding and direction.

Nevertheless, the program manager can exert significant effect on the evolution of the program. Interestingly, the changes do not seem to be the result of the disciplinary training of the manager but rather to 
the time and effort that the manager can dedicate to program leadership and the support that the manager can gain from other faculty members. We can conclude that managing an interdisciplinary program that has inconsistent support from higher administration can indeed be a challenge.

Our analysis of this history suggests five factors that are essential to interdisciplinary program success. We suspect that these factors are also important to the success of interdisciplinary programs elsewhere.

Energetic, dedicated and risk-taking program directors: Directors should (a) be knowledgeable of interdisciplinary organizational, curricular and pedagogical models; (b) be willing to seek support from outside parties for guidance and support; (c) be able to recruit faculty support even though rewards for that support are lacking; (d) be able to articulate a convincing argument for administrative support; (e) be willing to commit long hours to building support, developing proposals, generating reports and plans, mentoring a large number of students, stretching limited resources and remain accommodating in the face threats that arise from changing administrations and competing program initiatives; and most importantly (f) never lose sight of the value of interdisciplinary education.

Support from higher administration: Administrators should recognize the importance of interdisciplinary education and be willing to formulate and implement innovative solutions that lie outside of the typical "silo" mentality that still dominates higher education.

Support from affiliated faculty: Affiliated faculty should be willing to devote substantial time and effort to mentoring interdisciplinary students and serving on their committees with little or no recognition or reward from their home departments.

Cooperation with, or at least tolerance from, traditional departments: Traditional departments should (a) allow their faculty to teach interdisciplinary courses and mentor interdisciplinary students, (b) allow interdisciplinary students to take their courses and their students to take interdisciplinary courses, (c) provide support to interdisciplinary students when advised by their faculty, (d) recognize credit given to them when their faculty mentors interdisciplinary students and (e) allow the program to develop interdisciplinary courses even when elements of their disciplines are included.
Establishment of a sense of community: Shared identity and purpose among program faculty, alumni, students, employers and donors encourages professional exchange, mutual learning, social cohesion and program loyalty.

\section{CONCLUSION}

The last factor continues to pose the greatest challenge to our program. Students spend more time socializing with students in their advisors' departments than they do with each other. This not only alienates ES students from each other, but also discourages their participation in the activities of the ES student society. The provision of sufficient office space will produce a substantial leap forward.

Despite the challenges, however, the program has prospered and the future looks even better. Enrollment remains strong. Five new assistant professors recently joined our Steering Council (all women!). Faculty continues to provide support. External donations are growing. We remain hopeful that the move to the College of Arts and Sciences will provide increased financial and political support.

Perhaps most importantly, the current national mood seems ripe for a re-emergence of a political climate that favors environmental investment. Popular concerns over climate change, water security, energy independence, and sustainable development have reached threshold levels. This creates expanded opportunities for our program.

\section{ACKNOWLEDGEMENT}

The researchers thank Norman Durham, Richard Hecock, Jack Vitek, Paul Matthews, Gary Ostrander, Ed Knobbe, and Teresa Dustin for their contributions to this account of the history of our program.

\section{REFERENCES}

1. Rachel Carson, 2002. Silent Spring. 40 Anv Edn., Houghton Mifflin Company, Boston, ISBN: 10: 061825305X, pp: 400.

2. Dorothy Witter, A. and L. Maggie Payne, 1991. A History of the Oklahoma State University Graduate College. Oklahoma State University, Centennial Histories Series, pp: 257.

3. Craig Chappell, 1991. A History of Research at Oklahoma State University. Oklahoma State University, Centennial Histories Series, pp: 338. 